\title{
EL AMBIENTE ECOLÓGICAMENTE EQUILIBRADO COMO DERECHO FUNDAMENTAL DE LA TERCERA DIMENSIÓN: REFLEXIONES A PARTIR DE LA TUTELA CONSTITUCIONAL DE COSTA RICA
}

\author{
Carlos E. Peralta \\ Universidad de Costa Rica (UCR), Costa Rica \\ carlosperalta07@gmail.com
}

RESUMEN: El presente trabajo pretende analizar los alcances de la tutela jurídica del entorno natural a partir de la teoría de los derechos fundamentales, con la finalidad de que esa protección permita el ejercicio de las libertades y el respeto de los límites biofísicos y la resiliencia de la Naturaleza. Concretamente, se pretende estudiar la tutela constitucional del ambiente en Costa Rica con el objetivo de identificar sus características y realizar unas breves reflexiones sobre su posible fortalecimiento.

PALABRAS-CLAVE: Antropoceno. Tutela jurídica del ambiente natural. Derecho fundamental a un ambiente ecológicamente equilibrado. Costa Rica.

The ecologically balanced environment as a fundamental right of the third dimension: reflections from the constitutional protection of Costa Rica

\begin{abstract}
The purpose of this paper is to analyze the scope of the legal protection of the natural environment based on the theory of fundamental rights, with the aim of ensuring that this protection allows the exercise of freedoms and respect for the biophysical limits and resilience of Nature. Specifically, the aim is to study the constitutional protection of the environment in Costa Rica in order to identify its characteristics and make some brief reflections on its possible strengthening.
\end{abstract}

KEYWORDS: Anthropocene. Legal protection of the environment. Fundamental right to an ecologically balanced environment. Costa Rica

\section{O ambiente ecologicamente equilibrado como direito fundamental da terceira dimensão: reflexões a partir da tutela constitucional da Costa Rica}

\begin{abstract}
O artigo visa analisar a proteção jurídica do ambiente natural a partir da teoria dos direitos fundamentais, com a finalidade de que essa proteção permita o exercício pleno das liberdades e o respeito dos limites biofísicos e à resiliência da Natureza. Especificamente, o trabalho visa estudar a proteção constitucional do ambiente na Costa Rica com o objetivo de identificar as suas características e fazer algumas breves reflexões sobre seu possível fortalecimento. KEYWORDS: Antropoceno. Tutela jurídica do ambiente natural. Direito fundamental a um ambiente ecológicamente equilibrado. Costa Rica.
\end{abstract}


El ambiente ecológicamente equilibrado como derecho fundamental de la tercera dimensión. Reflexiones a partir de la tutela constitucional de Costa Rica

\title{
INTRODUCCIÓN
}

\author{
Que el nuestro sea un tiempo que se recuerde por el despertar de una nueva reverencia \\ ante la vida; por la firme resolución de alcanzar la sostenibilidad; por el acelera- \\ miento en la lucha por la justicia y la paz y por la alegre celebración de la vida. \\ (Carta de la Tierra)
}

La crisis ecológica que caracteriza al Antropoceno es un problema con una dimensión intergeneracional e inter-especies que pone en riesgo las fronteras de riesgo ecológico y, por ende, la resiliencia del planeta. La problemática ecológica es una característica y al mismo tiempo una consecuencia del modelo de desarrollo que fue adoptado en el pacto de la modernidad. El modus vivendi de la sociedad de riesgo está orientado por una irresponsabilidad organizada que desconsidera el valor intrínseco de la Naturaleza y su importancia para la sociedad. Ese modelo pareciera obviar que el entorno natural es el hogar que permite el desarrollo de las libertades humanas y ofrece las condiciones para la subsistencia de la sociedad como sistema autopoiético.

La actual crisis ecológica impone al Derecho la revisión de su estructura, de sus esquemas conceptuales y de sus respuestas prácticas, tanto a nivel legislativo como jurisprudencial. La complejidad ecológica exige que el Derecho vaya más allá de la perspectiva cartesiana y disyuntora que le ha caracterizado y que fue heredada de la primera modernidad, para poder, a partir de una perspectiva de Pensamiento Complejo, establecer diálogos inter y trans-disciplinarios que permitan reestructurar el modelo de desarrollo que caracteriza a la sociedad de riesgo; ese modelo de alta entropía compromete la sustentabilidad del Planeta y ha sido incapaz de ser prospectivo y de consolidar una justicia ecológica holística (intra/intergeneracional e inter-especies).

El Estado Constitucional de Derecho debe adquirir una vertiente ambiental, caracterizándose como un Estado Ecológico de Derecho capaz de conciliar los derechos liberales, los derechos sociales y los derechos ecológicos en un único proyecto jurídico político para la sociedad. Se deben fomentar/guiar las conductas y actividades que respeten la sustentabilidad ambiental, y desalentar aquellas que no lo hagan. Las normas jurídicas deben albergar los valores e instrumentos que permitan reeducar y transformar la sociedad, apuntando a la sustentabilidad.

El contexto que caracteriza el Antropoceno hizo que el tema ambiental adquiriera, a partir de la segunda mitad del siglo XX, una notable relevancia en la discusión de la teoría de los derechos fundamentales; la calidad ecológica constituye un requisito sine qua non para asegurar la vida en condiciones de dignidad, permitiendo el pleno desarrollo de las libertades y un estado de bienestar existencial. Así, desde la teoría de los derechos fundamentales es posible afirmar que la calidad ambiental está profundamente relacionada con los derechos de la personalidad y con la garantía de los derechos sociales. Al mismo tiempo, es innegable que la calidad ambiental exige ciertas restricciones a la libertad, concretamente en lo que respecta al ejercicio de actividades económicas que no respetan los límites ecológicos de la biosfera.

De acuerdo con esas consideraciones, el presente trabajo pretende analizar los alcances de la tutela jurídica del entorno natural a partir de la teoría de los derechos fundamentales, sin por ello negar la posibilidad de tutelar el entorno natural a partir de nuevos paradigmas -ecocéntricos o biocéntricos- que amplíen el horizonte de los derechos fundamentales. Concretamente, se pretende estudiar la tutela constitucional del ambiente en Costa Rica con la finalidad de identificar sus características y realizar unas breves reflexiones sobre su posible fortalecimiento. 


\section{LA CRISIS ECOLÓGICA QUE CARACTERIZA LA SOCIEDAD DE RIESGO DEL ANTROPOCENO:}

El ambiente es un elemento constitutivo e indispensable para la vida de los seres humanos. El ser humano tiene una relación de autonomía/dependencia dentro de dos niveles de auto organización: (1) la complejidad sociocultural que le proporciona su relativa independencia; y, (2) su complejo entorno natural, del cual es dependiente, y que al mismo tiempo le ofrece esa autonomía. El ser humano participa del entorno natural del cual forma parte, y dentro de él construye un núcleo sociocultural que está capacitado para la autorregulación (VICENTE GIMÉNEZ, 2002).

En esa relación de autonomía/dependencia radica la gran paradoja de la crisis ecológica: la independencia del ser humano está sujeta a los límites que le impone su entorno natural. Esta paradoja permite ver por qué muchos de los mayores retos a los que se enfrenta la sociedad actual, de una forma u otra, están relacionados con problemas ecológicos. Las circunstancias que caracterizan la crisis ecológica de la segunda modernidad instan a la prudencia y responsabilidad humana con respecto al entorno natural.

Desde la filosofía del racionalismo ilustrado, la relación homo-sapiens/naturaleza ha sido una relación tensa y de constante contradicción ${ }^{1}$. La sociedad actual se ha desarrollado sin integrar el elemento ecológico en sus procesos de decisión. En el modelo de desarrollo de la modernidad, la Naturaleza fue considerada como un objeto con utilidad, infinito, y que puede ser explotado sin restricciones. La agenda de desarrollo de los seres humanos se ha caracterizado por la apropiación (desigual) de los sistemas naturales para su propio beneficio, a menudo con un gran costo para otras especies y para el propio bienestar de la humanidad a largo plazo. La idea de desarrollo de la sociedad de la segunda modernidad ha perdido de vista que la Naturaleza tiene un valor intrínseco, es nuestro hogar y nuestra fuente de sustento.

Al respecto, Fraçois Ost (1997, p. 9) enseña que,

Mientras no sea repensada nuestra relación con la naturaleza y mientras no seamos capaces de descubrir lo que de ella nos distingue y lo que a ella nos vincula, nuestros esfuerzos serán en vano, como lo muestra la tan relativa efectividad del derecho ambiental y la tan modesta eficacia de las políticas públicas en este dominio. ${ }^{2}$

En las últimas décadas, las evidencias científicas muestran que la acción humana sobre el entorno natural ha provocado una crisis ecológica causada por los patrones de desarrollo económico. La forma e intensidad de la explotación del ambiente, así como las modalidades de producción/consumo/descarte de residuos, han provocado graves consecuencias para la Naturaleza, generando degradación, contaminación, cambio climático, pérdida de biodiversidad, erosión de suelo, sequías, deforestación, pobreza, etc. Actualmente, la huella ecológica de la humanidad es

\footnotetext{
1 Vicente Giménez (2002, p. 24) explica que "La explotación humana del medio natural ha existido siempre, el hombre ha incidido constantemente en el medio y provocado su regresión en distinta medida, pero el ecosistema ha ido superando con su propio mecanismo esta regresión, cuya intensidad no era superior a otras causas de regresión naturales. Es actualmente cuando el fenómeno alcanza connotaciones totalmente distintas, debido a que la explotación excesiva del hombre y la no conservación del medio natural determinan un proceso de grave regresión, una destrucción irreversible del ecosistema que llega a cuestionar la sucesión ecológica. En esta etapa civilizatoria, que coincide con la llamada revolución industrial y tecnológica, la explotación adquiere una nueva dimensión. Se trata de la explotación de la humanidad entera del conjunto de la biosfera como una unidad, lo que hace también universal la dispersión de los residuos e introduce como hábitos de vida del hombre moderno una desaforada explotación del medio ambiente del que se alimenta el metabolismo cultural. De este modo los ecosistemas humanizados (aquellos controlados por el hombre) detienen o invierten el proceso de sucesión".

2 Traducción propia del texto original consultado en portugués.
} 
El ambiente ecológicamente equilibrado como derecho fundamental de la tercera dimensión. Reflexiones a partir de la tutela constitucional de Costa Rica

superior a la biocapacidad del planeta. De modo que, a pesar del alto grado de desarrollo tecnológico y científico, paradójicamente, estamos viviendo una verdadera crisis ecológica que pone en peligro no solo el actual sistema de desarrollo sino, sobre todo, la resiliencia de la Naturaleza. Las consecuencias de la crisis ecológica del Antropoceno tienen un carácter global, transfronterizo y sinérgico y representan un enorme costo para la salud planetaria.

\section{Leff (2003, p. 27) explica que}

La crisis ambiental emerge así como la marca de una diferencia, la falta de un conocimiento, el haz en el que temporalizan y convergen los sentimientos pasados de la relación cultura-naturaleza y de donde divergen los sentidos polémicos y antagónicos de los discursos de la sustentabilidad: proyectando hacia un futuro insustentable las inercias del logocentrismo y la racionalidad económica dominante, o introyectando la ley límite de la entropía y los sentidos de la diversidad cultural.

Nuestra huella ecológica es la prueba de esta realidad. Según la Global Footprint Network, en 2020 rompimos nuestro presupuesto ecológico el 22 de agosto ${ }^{3}$. A partir de ese día, llegamos al llamado Día del Sobregiro de la Tierra. Ese año, utilizamos aproximadamente el $156 \%$ de los recursos y servicios ambientales que la naturaleza podía ofrecernos. Es decir, para mantener nuestro estilo de vida global, necesitamos aproximadamente 1,5 planeta al año. En otras palabras, la Tierra tarda un año y cinco meses en regenerar lo que usamos. A este ritmo, a mediados de la próxima década necesitaremos de dos planetas para sostener nuestra "demanda ecológica". Esta sobrecarga ecológica, tarde o temprano, comprometerá seriamente la calidad de vida de los seres humanos y de las otras especies, contribuyendo para generar conflictos socioambientales, migraciones masivas, hambre, enfermedades y el aumento de riesgos y catástrofes naturales. Infelizmente, el estilo de desarrollo actual favorece la cultura del despilfarro, de lo desechable. Así, en un círculo vicioso de consumismo, acabamos siendo fetiches de una cultura efímera que descuida el valor intangible de la naturaleza. La actual crisis ecológica es parte de un problema mayor: una crisis civilizatoria conformada por un complejo engranaje de crisis (sanitaria, intelectual, económica, nacional, etc...)

De manera que, nuestra época está marcada por la necesidad del despertar de una conciencia colectiva ante los riesgos ambientales; esta conciencia debe basarse en el valor de la solidaridad, y debe partir de la noción de dependencia de los seres humanos -y de los seres vivos en general- de su entorno natural.

\section{EL AMBIENTE ECOLÓGICAMENTE EQUILIBRADO: DERECHO Y DEBER FUNDAMENTAL ORIENTADO POR EL VALOR SOLIDARIDAD}

\subsection{La complejidad de las concepciones de ambiente}

Algunos autores señalan, con razón, que el término "medio ambiente" está compuesto por términos redundantes y que es más correcto hablar de ambiente o entorno ${ }^{4}$ En cuanto a la delimitación del concepto de ambiente, la tarea no es nada fácil. Existe un intenso e inacabado debate doctrinal sobre lo que debe entenderse por ambiente. El tema no es pacífico ni en el ámbito

3 Cf. Global Footprint Network. Disponible en: https://www.footprintnetwork.org. Acceso en: 22 abr. 2021.

4 Sobre el debate etimológico, entre otros, puede consultarse al Prof. Ramón Mateo (1991). 
jurídico ni en el campo del saber de las otras ciencias; se encuentran diversas opiniones al respecto, algunas definiendo el ambiente de forma más amplia, otras de forma más restringida, según los diversos elementos que se consideren.

La dificultad para delimitar el alcance del término ambiente se deriva de la propia complejidad de la realidad ecológica y del gran número de variables que intervienen. Su complejidad hace que se trate de un concepto inacabado y en constante evolución, siempre abierto a nuevos aspectos.

El término ambiente, por su propio significado, va más allá de cualquier tipo de pretensión simplificadora, no siendo posible señalar una definición global y definitiva. La pluralidad de significados y la amplitud del concepto son, sin duda, un gran reto para el derecho. En el plano de la ciencia jurídica existen innumerables definiciones del término ambiente y criterios encontrados sobre los elementos o aspectos relacionados. Sin embargo, existe un acuerdo sobre el carácter poliédrico y multidisciplinar del concepto jurídico de ambiente.

La posición jurídica sobre el tema debe tener como punto de partida la idea de que la realidad del entorno natural está anclada principalmente en la ecología. El legislador utiliza cada vez con más frecuencia un vocabulario técnico propio de la ecología, como, por ejemplo, equilibrio ecológico, hábitat, ecosistema, servicios ambientales, entre otros.

Con respecto al debate terminológico existente, actualmente se pueden identificar dos corrientes: la global y la reduccionista (JIMÉNEZ HERMÁNDEZ, 1998) . Los expositores de la primera corriente entienden que el ambiente está conformado por los diversos componentes naturales y por aspectos culturales y artificiales. Los autores que defienden la tesis reduccionista restringen el concepto de ambiente a determinados elementos del entorno natural.

Domper Ferrando, citado por Jiménez Hernández (1998, p.19-20), al analizar el concepto de ambiente, realizó una exhaustiva clasificación de las distintas posturas doctrinales, en la que pretende sintetizar los elementos que componen el ambiente y los aspectos que pueden incidir en él.

El autor señala la existencia de cinco grupos; cada uno de ellos, por regla general -pero no necesariamente- incluye los elementos de los anteriores: (1) Un primer grupo considera que el concepto de ambiente comprende los recursos naturales renovables (aire, agua, suelo, flora, fauna, protección de la naturaleza y espacios naturales) y los recursos naturales no renovables; (2) Una segunda postura considera que el concepto debe incluir también los elementos creados por el ser humano, como el patrimonio histórico y artístico, y otros aspectos y bienes culturales; (3) Un tercer sector introduce el urbanismo como parte del concepto; (4) Un cuarto grupo añade el ruido, las vibraciones, los residuos y las radiaciones; y, (5) Finalmente, una última corriente tiene como punto de referencia la vida humana y su entorno.

Según este análisis, en un sentido amplio, se puede afirmar que la comprensión del concepto de ambiente contempla la existencia de tres aspectos: (1) el entorno natural o físico; (2) el entorno artificial o social, incluidos los valores culturales, el espacio urbano y el entorno laboral; y (3) los diversos aspectos que inciden en el ambiente.

La noción estricta de ambiente está vinculada a su matriz ecológica, integrada por factores abióticos (agua, aire y suelo) y bióticos (fauna y flora); es el medio físico o natural. Esta posición permite entender el bien ambiental natural como una categoría jurídica unitaria, caracterizada principalmente por la idea de protección y conservación esencial de la diversidad biológica, el respeto de la resiliencia de la Naturaleza y por la interacción humana con el entorno natural dentro de las fronteras de riesgo ecológico, de modo que el impacto antropogénico no sea de tal magnitud que se convierta en daño. 
El ambiente ecológicamente equilibrado como derecho fundamental de la tercera dimensión. Reflexiones a partir de la tutela constitucional de Costa Rica

Así, el ambiente natural es un macro-bien de interés difuso o meta-individual, que se compone de una serie de micro-bienes interrelacionados e interdependientes. El entorno natural, como un todo solo puede comprenderse a partir de la interacción de sus partes, y estas solo pueden ser entendidas a partir del todo del cual son parte.

\subsection{Breves reflexiones sobre las formas de protección jurídica del ambiente natural y sobre el fenómeno de constitucionalización de la tutela jurídica del entorno físico}

La moderna protección jurídica del ambiente tiene su origen y desarrollo en los instrumentos de derecho internacional. La comunidad internacional comenzó a preocuparse más seriamente por el problema ambiental a finales de los años 60 y principios de los 70 . El Informe del Club de Roma de 1972 -conocido como Informe Meadows- lanzó la primera advertencia sobre los límites del crecimiento. En la Conferencia de las Naciones Unidas sobre el Medio Ambiente Humano, de 1972, se aprobó la Declaración de Estocolmo, para muchos el punto de partida del derecho ambiental moderno. Bajo la influencia de la Declaración de Estocolmo, la tutela jurídica del ambiente se convirtió en una tendencia internacional.

Con el consenso de la comunidad internacional sobre la importancia del derecho a un ambiente ecológicamente equilibrado como derecho humano indispensable para vivir en condiciones de dignidad, varios países empezaron gradualmente a proteger el ambiente en sus constituciones políticas.

Los primeros antecedentes pueden encontrarse incluso antes de la Declaración de Estocolmo. Entre finales de los años 50 y principios de los 70, algunas constituciones de los países de Europa del Este comenzaron a proteger el ambiente. La Constitución polaca, (1952) fue pionera en este ámbito, al establecer que toda persona tiene derecho a disfrutar de los valores del ambiente y el deber de defenderlos. Además, constituciones como las de Checoslovaquia (1960), Bulgaria (1971) y Hungría (1972) establecieron el deber del Estado de proteger el ambiente. Posteriormente, la protección constitucional del ambiente apareció en Europa Occidental en constituciones como la suiza (1971), la griega (1975), la portuguesa (1976) y la española (1978).

En América Latina, la preocupación por el tema ambiental se encuentra en varias constituciones, entre ellas: la Constitución de Panamá (1971), la cubana (1976), la chilena (1980), la hondureña (1982), la de El Salvador (1983), la de Haití (1985), la de Nicaragua (1987), la de México (1987), la Constitución Federal de Brasil (1988), la de Paraguay (1992), la de Argentina (con la reforma de 1994), la de Costa Rica (con la reforma de 1994), Ecuador (2008) y Bolivia (2009)

En términos generales, es posible afirmar que, en el siglo XX, la protección del ambiente fue marcada por tres tendencias:

(1) Un primer grupo de países, como Italia y Estados Unidos, protegen el ambiente incluso sin apoyo constitucional expreso. Italia, por ejemplo, reconoció el derecho al ambiente a través de una jurisprudencia basada en una interpretación extensiva de la Constitución, concretamente del art. 9.2, que se refiere a la protección del paisaje y del patrimonio histórico, y del art. 32, que protege el derecho a la salud.

(2) Un segundo grupo de naciones, como el caso de Grecia y Alemania (con la reforma de 1994) establecieron la protección del ambiente en sus constituciones como un objetivo 
del Estado, estableciendo un mandato para las autoridades puúblicas de proteger el ambiente natural.

(3) Finalmente, un tercer grupo de países, como Portugal, Brasil y Costa Rica, además de establecer la protección del ambiente como tarea y finalidad del Estado, han reconocido expresamente en sus constituciones el derecho fundamental de todas las personas a disfrutar de un ambiente ecológicamente equilibrado.

Además de esas tres primeras tendencias, en la primera década del Siglo XXI, surgió una cuarta tendencia de constitucionalizar la tutela constitucional ambiental. Ecuador ${ }^{5}$ y Bolivia ${ }^{6}$, en 2008 y 2009, respectivamente, adoptaron en sus Constituciones Políticas, al menos en la teoría, un paradigma ecocentrico, al reconocer los Derechos de la Naturaleza. Ambas constituciones adoptan la idea de "Buen vivir" como una especie de Meta-valor (al que otros valores más comunes deben supeditarse, como los de igualdad, inclusión y equidad social). Incluso el sistema educativo y el nuevo modelo económico deben ser guiados por el principio de Buen Vivir.

La discusión sobre el paradigma ecocéntrico paulatinamente ha ido ganando destaque, principalmente en los debates del ámbito académico.

Además de lo dispuesto en las Constituciones de Ecuador y Bolivia es posible apreciar el reconocimiento de los derechos de la naturaleza tanto en normas infraconstitucionales como a través del activismo judicial.

Así, por ejemplo, en la legislación de Nueva Zelanda, fue reconocido como sujeto de derechos el Parque Natural TE UREWERA, en la Isla Norte (2013) y el río WHANGANUI, venerado por los MAORÍES, también en la Isla Norte (2017). La legislación neozelandesa reconoció a ese río como una entidad viva ${ }^{7}$.

En lo que se refiere al activismo judicial progresista en materia ecológica, es posible encontrar ejemplos del reconocimiento de los derechos de la Naturaleza en la jurisprudencia constitucional colombiana y de la India.

En el caso de Colombia, el Tribunal Constitucional en Sentencia T-622-16 del 2016, se reconocieron derechos al Río Atrato $^{8}$. En esa sentencia el tribunal reconoció la existencia de derechos bio-culturales, de los cuales se desprende la conexión inseparable entre biodiversidad y diversidad cultural. Aunado a ello, ese Tribunal Constitucional ofreció una interpretación ampliada del derecho al agua al comprender que el agua posee en sí misma un valor irrefutable como parte esencial del ambiente, cuya existencia es necesaria para la vida de múltiples organismos y especies.

5 La Constitución ecuatoriana dispone sobre los Derechos de la Naturaleza en el Capítulo sétimo -arts71 a 74. Así, por ejemplo, el numeral 71 determina que: “Art. 71.- La naturaleza o Pacha Mama, donde se reproduce y realiza la vida, tiene derecho a que se respete integralmente su existencia y el mantenimiento y regeneración de sus ciclos vitales, estructura, funciones y procesos evolutivos.

Toda persona, comunidad, pueblo o nacionalidad podrá exigir a la autoridad pública el cumplimiento de los derechos de la naturaleza. Para aplicar e interpretar estos derechos se observaran los principios establecidos en la Constitución, en lo que proceda. El Estado incentivará a las personas naturales y jurídicas, y a los colectivos, para que protejan la naturaleza, y promoverá el respeto a todos los elementos que forman un ecosistema."

6 La Constitución boliviana establece: "Capítulo Quinto: derechos sociales y económicos. Sección I: Derecho al Medio Ambiente. Artículo 33.Las personas tienen derecho a un medio ambiente saludable, protegido y equilibrado. El ejercicio de este derecho debe permitir a los individuos y colectividades de las presentes y futuras generaciones, además de otros seres vivos, desarrollarse de manera normal y permanente."

7 Al respecto puede consultarse el trabajo de Catherine J. Iorns Magallanes (2015)

8 Disponible en: https://www.corteconstitucional.gov.co/relatoria/2016/t-622-16.htm. Acceso en: 21 abr. 2021 
El ambiente ecológicamente equilibrado como derecho fundamental de la tercera dimensión. Reflexiones a partir de la tutela constitucional de Costa Rica

Además de ese caso, mediante resolución STC 4360 del 2018, la Sala de Casación Civil de la Corte Suprema de Justicia de Colombia reconoció derechos a la Amazonia Colombiana9 .

En el caso de la India, el Tribunal Regional del Noreste de la India (Uttarakhand) emitió un fallo que otorgó protección a los ríos Ríos Yamuna y Ganghes al concebirlos como sujetos de derechos ${ }^{10}$; dicha decisión fue posteriormente revocada por la Corte Suprema de la India.

Independientemente de las observaciones críticas que puedan ser realizadas a la jurisprudencia colombiana e indiana desde el punto de vista del pluralismo jurídico, lo que cabe destacar es la apertura de esas instancias judiciales para discutir nuevos paradigmas para la tutela jurídica del ambiente; concepciones distintas del antropocentrismo clásico que entiende a la Naturaleza como recurso a servicio del ser humano. El paso a seguir será que los tribunales consoliden nuevos paradigmas permitiendo una participación más adecuada de las comunidades tradicionales involucradas de forma que puedan conocerse las distintas cosmovisiones existentes a fin de una adecuada protección y efectividad ecológica.

Finalmente, cabe destacar que a nivel internacional la Opinión Consultiva OC-23-17, del 15 de noviembre de $2017^{11}$ de la Corte Interamericana constituye un referente importante para la ecologización del derecho; En ese criterio la Corte entiende que en el sistema interamericano de derechos humanos, el derecho a un ambiente sano está consagrado en el artículo 11 del Protocolo de San Salvador. En esa Opinión, en síntesis, la Corte entendió que: (1). Toda persona tiene derecho a vivir en ambiente ambiente sano y a contar con servicios públicos básicos; y, (2). Los Estados parte promoverán la protección, preservación y mejoramiento del medio ambiente. Adicionalmente, este derecho también debe considerarse incluido entre los derechos económicos, sociales y culturales protegidos por el articulo 26 de la Convención Americana.

Si bien la interpretación de la Corte parte de una perspectiva antropocentrista, constituye un antecedente importante para el reconocimiento en América Latina del derecho al ambiente ecológicamente equilibrado como parte de los derechos humanos económicos, sociales, culturales y, ahora, ambientales: DESCA.

Aunado a las consideraciones realizadas, cabe indicar que, aunque la protección del ambiente es un fenómeno reciente que se manifiesta de forma diferente en los ordenamientos jurídicos de cada país, esa tendencia refleja la relevancia de la cuestión ambiental en nuestro tiempo y la exigencia de una transformación del modelo de desarrollo implantado a partir de la revolución industrial ${ }^{12}$.

Sin duda, la constitucionalización de la protección del entorno natural, en sus diversos grados, pone de manifiesto la incorporación de nuevos valores que provocarán un redimensionamiento del papel del Estado en la sociedad, tanto a nivel económico como político, ético y jurídico. Se acentúa la importancia del valor de la solidaridad, olvidado en el modelo clásico del Estado liberal.

Mientras que no se consolide una nueva racionalidad ecológica que permita superar el antropocentrismo vigente, adoptando paradigmas más holísticos, actualmente es posible reforzar

9 Disponible en: https://www.cortesuprema.gov.co/corte/wp-content/uploads/2018/04/STC4360-2018-2018-00319011.pdf. Acceso en: 21 abr. 2021

10 Al respecto consultar trabajo de Cano Pecharroman (2018)

${ }^{11}$ Disponible en: https://www.corteidh.or.cr/docs/opiniones/seriea 23 esp.pdf. Acceso en: 18 abr. 2021

12 Como destaca el Ministro Antônio Herman Benjamin (2007, p.68): "A experiência comparada parece indicar que, embora não necessariamente imprescindível, o reconhecimento constitucional expresso de direitos e deveres ambientais é, jurídica e praticamente, benéfico, devendo, portanto, ser estimulado e festejado. Um regime constitucional cuidadosamente redigido, de modo a evitar dispositivos nebulosos e de sentido incerto, pode muito bem direcionar e até moldar a política nacional do meio ambiente". 
la tutela del entorno natural a partir de una adecuada aplicación de la teoría de los derechos fundamentales. Así, a partir de esa teoría, podemos entender que, desde una perspectiva objetiva, la calidad del ambiente constituye un objetivo constitucional que determina la obligación del Estado de garantizar el respeto y la protección del ambiente. El Estado deberá desempeñar un papel importante en la adopción de políticas públicas que protejan y garanticen efectivamente el derecho al ambiente, de manera que las diversas actividades antropogénicas respeten los límites biofísicos determinados por el conocimiento científico. Así, la constitucionalización del ambiente natural revela la adopción de una nueva postura ética, en la que la Naturaleza no puede ser vista únicamente desde una perspectiva económica; el bien ambiental no es un recurso al servicio del Homo Sapiens.

El Estado moderno debe asumir necesariamente, como una de sus características, una vertiente ecológica, y debe aspirar a promover modelos de desarrollo que respeten los límites planetarios. Este modelo de Estado se proyecta axiológicamente sobre el valor de la solidaridad, con una perspectiva esencialmente comunitaria.

Tiago Fensterseifer (2008 p.97) explica que el modelo de Estado Ecológico (Socio-ambiental), al combinar las conquistas positivas (en términos de protección de la dignidad humana) de los modelos de Estado de Derecho anteriores, incorpora también la protección de nuevos derechos trans-individuales y, en un paradigma de solidaridad humana (en las dimensiones nacional, supranacional e intergeneracional), pretende proyectar la comunidad humana a un nivel más avanzado en la realización de los derechos fundamentales (especialmente los nuevos derechos de tercera dimensión) y la realización de una vida humana digna y saludable para todos sus miembros.

\subsection{El derecho al ambiente ecológicamente equilibrado como requisito sine}

\section{qua non de la calidad de vida y la dignidad humana}

Desde la teoría de los derechos fundamentales, los nuevos retos de la sociedad del riesgo nos obligan a hablar de una dimensión ecológica de la dignidad humana que además, a partir de la idea de alteridad, extiende una responsabilidad del ser humano para con la vida de las otras especies.

El derecho a disfrutar de un ambiente en condiciones ecológicamente equilibradas es uno de los llamados derechos de la tercera dimensión, basados en el valor de la solidaridad -o fraternidad- que surgen como consecuencia de la contaminación de las libertades.

Los derechos difusos, aunque integran la categoría de derechos fundamentales, como enseña el profesor Ricardo Lobo Torres (2001, p.300), "no son derechos de libertad, clasificándolos más bien como derechos de solidaridad, ya que su cumplimiento depende también de la conciencia de los deberes y del culto a la fraternidad".

El derecho a la calidad ambiental limita la libertad para protegerla ${ }^{13}$. Ese derecho tiene una estrecha relación con el derecho a la salud y el derecho a la vida de las generaciones presentes

${ }^{13}$ Al respecto, Maria da Gloria F. P. D. (2007, p.485-486) explica: “A protecção ambiental, que é também a proteção da liberdade, corresponde a uma afetação da liberdade, uma sua limitação - protecção da liberdade e afetação da liberdade correspondem-se. Compreende-se, neste contexto, que sempre que juridicamente se procura definir a proteção ambiental, essa definição faça intervir uma reflexão ética, enquanto controlo do homem sobre si próprio, num enquadramento alargado de responsabilidade pelo futuro e num plano de construção de uma justiça funda e alargada, intra e intergeracional. (...) A projeção ambiental envolve, por isso, um controlo do homem sobre si próprio, em razão do 
El ambiente ecológicamente equilibrado como derecho fundamental de la tercera dimensión. Reflexiones a partir de la tutela constitucional de Costa Rica

y futuras. El ser humano necesita el ambiente para su salud física y mental, para el desarrollo de su personalidad y para disfrutar de una calidad de vida adecuada. Además, esa calidad ambiental solo es posible sí el ser humano respeta los procesos ecológicos esenciales.

El derecho fundamental al ambiente está estrechamente relacionado con los derechos de la personalidad, ya que vivir en un entorno degradado compromete el libre desarrollo de la personalidad humana, especialmente en lo que respecta a la integridad psicofísica del ser humano. El ser humano vive y sobrevive dentro del entorno natural del cual forma parte.

Por otro lado, la idea de sustentabilidad que debe guiar el Estado Ecológico Derecho exige la defensa del ambiente respetando los procesos ecológicos esenciales y la resiliencia de la Naturaleza, así como también requiere considerar aspectos de justicia ecológica distributiva. La protección del ambiente deberá estar directamente relacionada con la garantía de los derechos sociales, ya que el disfrute de estos últimos en los niveles deseables está necesariamente ligado a condiciones ambientales favorables, que garanticen el mínimo vital ecológico, el acceso al agua potable, el saneamiento básico, el derecho a la vivienda y al trabajo en lugares no amenazados por riesgos ambientales, la igual de género, el respeto de los pueblos originarios, el derecho a la educación etc. El pleno desarrollo del ser humano y el aumento de su calidad de vida sólo será posible en un ambiente natural adecuado.

De manera que, el derecho a un ambiente ecológicamente equilibrado es un derecho que parte del vínculo inseparable entre el ser humano y su entorno natural, constituyendo un parámetro fundamental para garantizar la vida en condiciones de libertad, igualdad y dignidad. La calidad del ambiente es un requisito sine qua non para una vida plena y saludable. En consecuencia, deben existir normas ambientales mínimas que, orientadas por el principio precautorio y por los principios de progresividad y no regresión, permitan el pleno desarrollo de la existencia humana dentro de un entorno natural de calidad. Existe una relación de correspondencia entre la calidad ambiental y la calidad de vida. La subjetivización de la cuestión ambiental parte del reconocimiento de un derecho fundamental a la calidad de vida de los seres humanos, ya que el ambiente determina y condiciona el concepto de calidad de vida.

\subsection{La doble perspectiva del derecho (y del deber) fundamental al ambiente ecológicamente equilibrado}

El derecho a un ambiente ecológicamente equilibrado participa de la doble funcionalidad de los derechos fundamentales: es un derecho fundamental de los ciudadanos y un valor común de la sociedad que orienta la conducta de los individuos y dirige la acción del Estado.

En cuanto a la dimensión subjetiva, por su propia naturaleza, el macro-bien ambiental no es susceptible de apropiación individual. En consecuencia, debe entenderse que el derecho al ambiente es de interés difuso; en tesis, este derecho es de titularidad trans-individual -no pertenece a una persona o grupo claramente determinado-, pertenece a toda la sociedad. Es un derecho de dimensión difusa, que afecta a todas las personas sin distinción. Sin embargo, hay que señalar que el derecho al ambiente, aunque sea de carácter difuso o trans-individual, es un derecho que

próprio homem, (...) Em suma, a liberdade de agir é limitada em razão da protecção da liberdade, entendida em termos de contemporaneidade e em termos de futuro, e entendida também como um momento essencial da protecção ambiental". 
pertenece a todos y a cada uno individualmente ${ }^{14}$. En otras palabras, a pesar de su carácter difuso, este derecho tiene también una perspectiva individual y subjetiva, en la medida en que el daño ambiental puede afectar tanto a la comunidad como al individuo, que tiene derecho a defender su derecho subjetivo.

Por otra parte, desde una perspectiva objetiva, la calidad del ambiente representa un valor para toda la comunidad estatal. Se trata de un mandato constitucional que determina la obligación del Estado de velar por el respeto y la protección del ambiente a través de mecanismos de prevención, de promoción de comportamientos ecológicamente sustentables (como sería el caso de los instrumentos económicos) o de mecanismos sancionadores. Por otro lado, la dimensión objetiva también exige el deber de todos los ciudadanos de respetar y proteger el ambiente para vivir en condiciones de libertad y dignidad.

Una característica interesante de este deber fundamental es que su cumplimiento está relacionado con la existencia de la sociedad y no con la existencia del Estado ${ }^{15}$. Es un derechodeber que encuentra fundamento en el valor de la solidaridad y que debe estar orientado por los principios de sustentabilidad, esencialidad ambiental y equidad intergeneracional. Esta perspectiva del derecho/deber tiene dos implicaciones importantes:

(1) Por un lado, permite una proyección particular del carácter intergeneracional. Requiere que la sociedad asuma la responsabilidad de conservar las condiciones ambientales que permiten la vida tanto ahora como en el futuro. De este modo, aunque las próximas generaciones no tengan todavía un derecho subjetivo sobre el ambiente, tendrán la posibilidad de vivir en condiciones de calidad ambiental. Nuestros futuros herederos tienen garantizada la titularidad potencial de su derecho subjetivo.

El ambiente es patrimonio común de todas las generaciones, y su protección tiene una dimensión ética de solidaridad con el futuro que apunta a la continuidad del género humano y a la estabilidad de la vida en el planeta. La solidaridad tiene una dimensión intergeneracional.

(2) En segundo lugar, la dimensión objetiva permite, a través de la noción de deber fundamental, una protección entre especies guiada por una ética de la sustentabilidad-justicia

${ }^{14}$ Sobre el tema Tiago Fensterseifer (2007, p. 149-150) expressa: “Os direitos fundamentais de terceira dimensão (direitos de solidariedade ou fraternidade) são de titularidade proeminentemente transindividual (difusa e coletiva), revelando um conteúdo altamente humanista e universal. A marca distintiva dos direitos de terceira dimensão, portanto, reside basicamente na sua natureza transindividual, com titularidade muitas vezes indefinida e indeterminável, o que se revela especialmente no direito ao ambiente (...)". No entanto, adverte o autor que, no caso do direito ao ambiente, "pese a habitual presença do interesse coletivo ou difuso, não deixa de objetivar também a proteção da vida e da qualidade de vida do homem na sua individualidade". Outro aspecto importante destacado pelo autor com relação ao direito fundamental em questão diz respeito à indivisibilidade do seu objeto, toda vez que a qualidade ambiental é um bem de natureza eminentemente difusa, compreendendo o equilíbrio de todo o ecossistema natural".

15 José Casalta Nabais (1998, p. 52-53) sobre la simetría existente entre el derecho al ambiente y el deber de protección explica que "a associação destes deveres aos correspondentes direitos é de tal modo forte que justifica a autonomizacão destes como 'direitos de solidariedade', 'direitos poligonais' ou 'direitos circulares' cujo conteúdo é definido necessariamente em função do interesse comum, pelo menos em tudo quanto ultrapasse a lesão de bens individuais, tendo assim a sua dimensão objetiva um peso bem maior do que é próprio dos direitos fundamentais em geral. Dada esta sua estrutura, tais direitos também são designados 'direitos boomerang' ou direitos com efeito 'boomerang', já que eles são, por um lado, direitos e, por outro lado, deveres para o respectivo titular activo, ou seja, direito que, de algum modo, acabam por se voltar contra os próprios titulares.

Aqui se devem integrar, a nosso ver, os deveres para com os nossos companheiros da aventura humana - os animais, as plantas e até os rios, os mares - que, ao contrário do que por vezes se ousa afirmar, não constituem direitos (humanos!) dos animais, das plantas, dos rios e dos mares. Evidentemente que em tais domínios se trata dum conjunto de deveres indiretos para com a humanidade, ou mais precisamente, de exigências correspondentes a um equilibrado e adequado ambiente natural necessário à preservação da vida (digna de ser vivida) da espécie humana, integrada esta tanto pela geração atual como pelas gerações futuras". 
El ambiente ecológicamente equilibrado como derecho fundamental de la tercera dimensión. Reflexiones a partir de la tutela constitucional de Costa Rica

ecológica inter-especies ${ }^{16}$. Por lo que existe el deber de todos los seres humanos de respetar los límites biofísicos del planeta, garantizando su protección y conservación.

Por otro lado, es importante destacar que, en el ámbito de la protección del ambiente natural, cobra especial relevancia la eficacia inmediata entre particulares (drittwirkung) irradiada por la dimensión objetiva del derecho fundamental al ambiente, ya que buena parte de las actividades contaminantes son realizadas por particulares que se encuadran en las relaciones de carácter vertical. Por lo general, existe una relación desigual con respecto al poder social, económico y técnico que ejerce el empresario privado de las actividades que dañan o pueden degradar el medio ambiente.

A partir de los deberes ambientales fundamentales y de la eficacia horizontal, el individuo tendrá derecho -posición jurídica subjetiva- a exigir la abstención (perspectiva defensiva) de la injerencia privada en el ámbito de protección de su derecho fundamental al ambiente; o podrá exigir una conducta positiva (perspectiva prestacional) a los actores privados directamente responsables de la vulneración de su derecho fundamental.

El enfoque derecho-deber fundamental permite esbozar un modelo de protección del ambiente que aleja al Estado de la condición de único guardián de la naturaleza e inserta a los particulares en las filas permanentes de los defensores del entorno natural, imponiendo una serie de deberes a los individuos, como las obligaciones vinculadas a la función socioambiental de la propiedad.

El derecho a un ambiente ecológicamente equilibrado tiene un status negativus (aspecto defensivo) y un status positivus (aspecto prestacional). En su característica negativa, es un derecho que dota a los ciudadanos de los instrumentos jurídicos necesarios para proteger la naturaleza de las acciones que la perjudican, de manera que ni el Estado ni los particulares puedan invadir el ámbito de protección del derecho, comprometiendo o rompiendo el equilibrio ambiental.

Por otro lado, el estatus positivo requiere intervenciones positivas por parte del Estado para la realización del derecho -ya sea para la protección o la restauración del ambiente- y el deber de los ciudadanos de respetar la calidad del medio ambiente.

Alexy (2001, p.49) considera que el derecho al ambiente es un derecho fundamental como un todo: (1) es un derecho de defensa, en el sentido de que el Estado debe omitir determinadas intervenciones en el ambiente; (2) es un derecho de protección que supone el deber del Estado de proteger a los ciudadanos frente a las intervenciones de terceros; (3) es un derecho de procedimiento, que exige información adecuada, participación ciudadana en asuntos relevantes para el ambiente y acceso a la justicia; y (4) es un derecho prestacional que se traduce en la adopción de medidas por parte del Estado para mejorar la calidad ambiental.

En resumen, la satisfacción de este derecho-deber requiere:

(1) La abstención total de los particulares y del Estado de contaminar y de afectar negativamente el equilibrio ecológico; (2) El deber de proteger el medio natural; (3) El uso racional y equitativo de los recursos ambientales; y (4) Las obligaciones positivas por parte del Estado.

El deber fundamental de proteger el ambiente da lugar a obligaciones negativas y positivas, vinculadas a la función socioambiental de la propiedad. Por un lado, se exige la abstención de conductas que dañen el ambiente y, por otro, se imponen comportamientos positivos a los

${ }^{16}$ Sobre la justicia ecológica inter-especies pueden consultarse a Peralta (2011). 
actores privados, exigiendo la adopción de conductas específicas para prevenir y reparar cualquier forma de degradación ambiental que esté relacionada con el ejercicio de los derechos de propiedad.

\section{DERECHO FUNDAMENTAL AL AMBIENTE ECOLÓGICAMENTE EQUILIBRADO EN COSTA RICA}

En el caso de Costa Rica, en 1994 se introdujeron dos párrafos al artículo 50 de la Constitución para proteger expresamente el derecho a un ambiente ecológicamente equilibrado. Antes de esta reforma constitucional, la Constitución Política de Costa Rica (CP/49), que data de 1949, no reconocía de manera formal el derecho fundamental al ambiente.

Cabe resaltar que la celebración de la Conferencia de las Naciones Unidas sobre Medio Ambiente y Desarrollo, celebrada en Rio de Janeiro en 1992, fue determinante para que el Tribunal Constitucional costarricense (Sala IV), reconociera, en 1993, la materialidad de ese derecho fundamental. Así, la Sala IV, a partir de una interpretación sistemática de los artículos 21, 50 y 89 constitucionales, en concordancia con las disposiciones de instrumentos internacionales de "soft law", a partir de la visión antropocentrica imperante en la época, reconoció, la calidad ambiental como un derecho fundamental, considerando su importancia para la vida, y para el bien estar físico y psicológico de los seres humanos.

Al respecto, el Tribunal Constitucional de Costa Rica, plasmo las bases para el reconocimiento material del derecho fundamental al ambiente ecológicamente equilibrado en el Voto $3705-93^{17}$, explicando que:

Hasta la década de 1970, la preocupación por el medio ambiente se mantuvo en un nivel bajo, con variantes en ciertos sectores, situación que se reflejó en nuestra legislación; no obstante, a partir de ese año, con el despertar de la conciencia ambiental global, Costa Rica empezó a inquietarse. Nuestro país ha dependido y seguirá dependiendo, al igual que cualquier otra nación, de sus recursos naturales y su medio ambiente para llenar las necesidades básicas de sus habitantes y mantener operando el aparato productivo que sustenta la economía nacional, cuya principal fuente la constituye la agricultura y, en los últimos años, el turismo, especialmente en su dimensión de ecoturismo. El suelo, el agua, el aire, los recurso marinos y costeros, los bosques, la diversidad biológica, los recursos minerales y el paisaje conforman el marco ambiental sin el cual las demandas básicas -como espacio vital, alimentación, energía, vivienda, sanidad y recreación- serían imposibles. De igual modo, nuestra economía también está íntimamente ligada al estado del ambiente y de los recursos naturales; así, por ejemplo, tanto la generación de divisas por explotación agrícola y turística, como el éxito de importantes inversiones en infraestructura dependen, en última instancia, de la conservación de aquéllos. Las metas del desarrollo sostenible tienen que ver con la supervivencia y el bienestar del ser humano y con el mantenimiento de los procesos ecológicos esenciales, es decir, de la calidad ambiental y de la sobrevivencia de las otras especies. Hablar de desarrollo sostenible en términos de satisfacción de las necesidades humanas presentes y futuras y del mejoramiento de la calidad de vida es hablar de la demanda de los recursos naturales a nivel individual y de los medios directos o de apoyo necesarios para que la economía funcione generando empleo y creando los bienes de capital, que a su vez hagan posible la transformación de los recursos en productos de consumo, de producción y de exportación.

\section{(...)}

Nuestro país ha suscrito gran cantidad de convenciones en las que se busca la protección de los recursos naturales y que deben utilizarse para integrar la legislación in-

\footnotetext{
17 Voto disponible en: https://vlex.co.cr/vid/-497243742. Acceso en: 21 abr. 2021
} 
El ambiente ecológicamente equilibrado como derecho fundamental de la tercera dimensión. Reflexiones a partir de la tutela constitucional de Costa Rica

terna y dilucidar, incluso jurisdiccionalmente, los problemas relacionados con la protección ambiental, ya que los instrumentos internacionales, aún los no ratificados, permiten soluciones regionales o mundiales a tales problemas.

V) - La vida humana sólo es posible en solidaridad con la naturaleza que nos sustenta y nos sostiene, no sólo para alimento físico, sino también como bienestar psíquico: constituye el derecho que todos los ciudadanos tenemos a vivir en un ambiente libre de contaminación, que es la base de una sociedad justa y productiva. Es así como el artículo 21 de la Constitución Política señala: La vida humana es inviolable. Es de este principio constitucional de donde innegablemente se desprende el derecho a la salud, al bienestar físico, mental y social, derecho humano que se encuentra indisolublemente ligado al derecho de la salud y a la obligación del Estado de proteger de la vida humana.

Asimismo, desde el punto de vista psíquico e intelectual, el estado de ánimo depende también de la naturaleza, por lo que también al convertirse el paisaje en un espacio útil de descanso y tiempo libre es obligación su preservación y conservación. Aspecto este último que está protegido en el artículo 89 constitucional, el cual literalmente dice: Entre los fines culturales de la República están: proteger las bellezas naturales, conservar y desarrollar el patrimonio histórico y artístico de la Nación, y apoyar la iniciativa privada para el progreso científico y artístico. Proteger la naturaleza desde el punto de vista estético no es comercializarla ni transformarla en mercancía, es educar al ciudadano para que aprenda a apreciar el paisaje estético por su valor intrínseco. (El resaltado no es del original)

Como puede apreciarse, esa resolución, al igual que la Declaración de Rio sobre Medio Ambiente y Desarrollo y la denominada Agenda 21 - Programa Global para el desarrollo sostenible en el siglo 21-, entendió que la protección de la naturaleza y la idea de desarrollo sostenible están ancladas a una perspectiva antropocéntrica y a la perspectiva del uso racional de los recursos para permitir el crescimento económico.

Sobre influencia de esa jurisprudencia constitucional y de instrumentos internacionales ambientales, en 1994, mediante enmienda constitucional, fue formalmente reconocido el derecho fundamental a un ambiente ecológicamente equilibrado, ampliándose lo que estaba dispuesto en el artículo 50 constitucional. Originalmente, ese artículo establecía que "El Estado procurará el mayor bienestar a todos los habitantes del país, organizando y estimulando la producción y el más adecuado reparto de la riqueza" Ese numeral se encuentra en el Título V sobre Derechos y Garantías Sociales.

Con la enmienda constitucional - Reforma introducida a través de la Ley n. 7.412, de 3 de junio de 1994- el artículo 50, ubicado en el Título V sobre derechos y garantías sociales, quedó redactado de la siguiente forma:

\begin{abstract}
ARTÍCULO 50.
El Estado procurará el mayor bienestar a todos los habitantes del país, organizando y estimulando la producción y el más adecuado reparto de la riqueza

Toda persona tiene derecho a un ambiente sano y ecológicamente equilibrado. Por ello, está legitimada para denunciar los actos que infrinjan ese derecho y para reclamar la reparación del daño causado.

El Estado garantizará, defenderá y preservará ese derecho.

La ley determinará las responsabilidades y las sanciones correspondientes.

(Así reformado por el artículo $1^{\circ}$ de la Ley No.7412 de 3 de junio de 1994) ${ }^{18}$
\end{abstract}

${ }^{18}$ Cabe señalar que, en la exposición de motivos del proyecto de reforma constitucional, Expediente n. 10.649 de la Asamblea Legislativa de Costa Rica, se indicó que: “(...) Los derechos contemporáneos forman la llamada “tercera generación" ... Entre los nuevos derechos - que implican, también deberes - está el de vivir en un ambiente puro, que abarque la protección de todo el entorno natural del hombre... El hombre debe tener la sabiduría de hacer un uso 
Además de esa primera reforma, en 2020, mediante enmienda constitucional, la ley $\mathrm{N}^{\circ}$ 9849, de 05 de junio de 2020, introdujo un nuevo párrafo en el citado artículo 50 reconociendo el derecho de acceso al agua para los seres humanos.

\begin{abstract}
Toda persona tiene el derecho humano, básico e irrenunciable de acceso al agua potable, como bien esencial para la vida. El agua es un bien de la nación, indispensable para proteger tal derecho humano. Su uso, protección, sostenibilidad, conservación y explotación se regirá por lo que establezca la ley que se creará para estos efectos y tendrá prioridad el abastecimiento de agua potable para consumo de las personas y las poblaciones.
\end{abstract}

(Así adicionado el párrafo anterior por el artículo $1^{\circ}$ de la ley $N^{\circ} 9849$ del 5 de junio del 2020, "Reconocer y garantizar el derecho humano de acceso al agua")

Consideramos que, si bien esa última enmienda constitucional es relevante, la misma fue tímida, perdiéndose la oportunidad de una reforma más holística que permitiese una tutela y una comprensión multifocal de los recursos hídricos. Esa reforma se limitó al reconocimiento de una perspectiva antropocentrista y utilitarista del agua, sin considerar, por ejemplo, aspectos relacionados con la dimensión bio-cultural del agua, o la importancia del derecho al saneamiento básico, entre otros.

De las consideraciones realizadas sobre la tutela constitucional del ambiente en Costa Rica es posible concluir que: (1). El ambiente ecológicamente equilibrado como derecho fundamental fue reconocido de manera material en 1993 vía jurisprudencia constitucional; (2). Formalmente ese derecho es reconocido en 1994 en la Constitución de Costa Rica en el Título V sobre derechos y garantías sociales; (3). El artículo 50 tutela el ambiente natural en sentido estricto, al referirse claramente al derecho de los seres humanos a un medio ambiente ecológicamente equilibrado, es decir, al medio físico o natural, excluyendo el medio artificial -social o construido, y; (4). En Costa Rica no hay un capítulo de garantías ambientales en la Constitución. El artículo 50 que reconoce el derecho a un ambiente ecológicamente equilibrado y el derecho al acceso al agua potable tienen un carácter marcadamente antropocentrista y tiene imprecisiones de técnica legislativa desconsiderando la moderna epistemología ecológica.

En nuestro criterio, es necesario un capítulo de garantías ambientales en la Constitución costarricense, elaborando a partir de una perspectiva multifocal y con una técnica legislativa más coherente y consistente, apoyada por el conocimiento científico y el diálogo de saberes. Las dos enmiendas, pese a su buena intención, parecen iniciativas "casuísticas", que dejan el 50 constitucional como una especie de "Frankenstein normativo" con pequeñas "curitas verdes" en un capítulo dedicado a derechos sociales. Ese "Frankenstein normativo esverdeado" pareciera estar principalmente orientado por un antropocentrismo que objetiva el crecimiento económico a partir de la "utilidad" que los recursos naturales tienen para el ser humano. En cambio, una perspectiva multifocal, que integre la complejidad ecológica, exigiría contemplar, en un robusto capítulo ambiental constitucional, por ejemplo, a las comunidades indígenas, el respeto de los procesos ecológicos esenciales, el derecho a la ciudad, los principios del derecho ecológico, la técnica tributaria para la defensa ecológica, la sustentabilidad como criterio para orientar el orden económico, etc.

racional de la naturaleza, sin dañarla o destruirla... Las reformas constitucionales que se presentan tienen como propósito resaltar el derecho de todo habitante de Costa Rica, a disfrutar de un ambiente puro, lo mismo que de un desarrollo ecológico equilibrado y sano, conforme con la ley y los tratados internacionales... Por otra parte, existe una obligación internacional, que cada vez cobra más fuerza en la comunidad de naciones, de establecer una cooperación estrecha para realizar las mismas tareas de proteger el ambiente y los recursos naturales (...).” 
El ambiente ecológicamente equilibrado como derecho fundamental de la tercera dimensión. Reflexiones a partir de la tutela constitucional de Costa Rica

Cabe indicar que el tribunal constitucional costarricense, apegado a la literalidad de la norma constitucional, ha tenido una posición conservadora, adoptando en reiterada jurisprudencia un paradigma marcadamente antropocentrico, que acepta el débil oxímoron del desarrollo sostenible. Ese oxímoron entiende bienestar como sinónimo de crecimiento económico constante con pequeños parches verdes, de forma que, a partir de una visión utilitarista se puede explotar los recursos naturales en un contexto de irresponsabilidad organizada.

La posición del Tribunal Constitucional costarricense puede apreciarse en algunas resoluciones colocadas en el siguiente cuadro:

Cuadro 1. Posición antropocentrista de la Sala IV en materia ambiental

\begin{tabular}{|c|c|}
\hline Resolución/voto & Contenido \\
\hline $\mathrm{N}^{\mathrm{o}} 3705-1993^{19}$ & $\begin{array}{l}\text { "Hablar de desarrollo sostenible en términos de satisfacción de las necesidades } \\
\text { humanas presentes y futuras y del mejoramiento de la calidad de vida es hablar de } \\
\text { la demanda de los recursos naturales a nivel individual y de los medios directos o } \\
\text { de apoyo necesarios para que la economía funcione generando empleo y creando } \\
\text { los bienes de capital, que a su vez hagan posible la transformación de los recursos } \\
\text { en productos de consumo, de producción y de exportación". }\end{array}$ \\
\hline $\mathrm{N}^{\circ} 1763-1994 .^{20}$ & $\begin{array}{l}\text { "El desarrollo sostenible es una de esas políticas generales que el Estado dicta para } \\
\text { ampliar las posibilidades de que todos puedan colmar sus aspiraciones a una vida } \\
\text { mejor, incrementando la capacidad de producción o bien, ampliando las posibili- } \\
\text { dades de llegar a un progreso equitativo entre un crecimiento demográfico o entre } \\
\text { éste y los sistemas naturales. } \\
\text { Es el desarrollo sostenible, el proceso de transformación en la utilización de los } \\
\text { recursos, orientación de las inversiones, canalización del desarrollo tecnológico, } \\
\text { cambios institucionales y todo aquello que coadyuve para atender las necesidades } \\
\text { humanas del presente y del futuro." }\end{array}$ \\
\hline $\mathrm{N}^{\mathrm{o}} .6938-2000 .^{21}$ & $\begin{array}{l}\text { "Por ejemplo, se producen problemas ambientales cuando las modalidades de ex- } \\
\text { plotación de los recursos naturales dan lugar a una degradación de los ecosistemas } \\
\text { superior a su capacidad de regeneración, lo que conduce a que amplios sectores de } \\
\text { la población resulten perjudicados y se genere un alto costo ambiental y social que } \\
\text { redunda en un deterioro de la calidad de vida; pues precisamente el objetivo pri- } \\
\text { mordial del uso y protección del ambiente es obtener un desarrollo y evolución } \\
\text { favorable al ser humano. La calidad ambiental es un parámetro fundamental de esa } \\
\text { calidad de vida; otros parámetros no menos importantes son salud, alimentación, } \\
\text { trabajo, vivienda, educación, etc., (...)" }\end{array}$ \\
\hline $\mathrm{N}^{\circ} 01594-2013^{22}$ & $\begin{array}{l}\text { "VII. Sobre la alegada violación al principio de desarrollo sostenible y del artículo } \\
50 \text { constitucional. La accionante invoca la violación del principio constitucional } \\
\text { de desarrollo sostenible derivado del artículo } 50 \text { de la Carta Magna, por prohibir } \\
\text { una actividad productiva compatible con el respeto al ambiente y que coadyuva a } \\
\text { la creación de riqueza y empleo para el país. Es técnicamente posible que la ex- } \\
\text { plotación de la minería metálica a cielo abierto se haga con respeto absoluto al } \\
\text { medio ambiente, y que la utilización de compuestos químicos como el mercurio o } \\
\text { el cianuro no dañan el ambiente si son manejados adecuadamen. Para la Sala no } \\
\text { es casualidad que el derecho a un ambiente sano y ecológicamente equilibrado se } \\
\text { haya regulado en el artículo } 50 \text { constitucional, numeral que le otorga al legislador } \\
\text { las potestades para la organización y estímulo de la producción y para el más ade- } \\
\text { cuado reparto de la riqueza, potestades que de conformidad con la norma deben } \\
\text { ser ejercidas en procura de un fin definido constitucionalmente: el mayor bienestar }\end{array}$ \\
\hline
\end{tabular}

\footnotetext{
19 Voto disponible en: https://vlex.co.cr/vid/-497243742. Acceso en: 21 abr. 2021

${ }^{20}$ Voto disponible en: https://nexuspj.poder-judicial.go.cr/document/sen-1-0007-95161. Acceso en: 21 abr. 2021

${ }^{21}$ Voto disponible en: https://nexuspj.poder-judicial.go.cr/document/sen-1-0007-138238. Acceso en: 21 abr. 2021

22 Voto disponible en: https://nexuspj.poder-judicial.go.cr/document/sen-1-0007-566169. Acceso en: 21 abr. 2021
} 


\begin{tabular}{|l|l|}
\hline & de todos los habitantes. Dentro del término "mayor bienestar" encontramos no solo \\
una política orientada a un mayor desarrollo económico, sino también una política \\
redistributiva, dirigida a lograr la distribución de la riqueza producto de la coope- \\
ración social. Tanto la una como la otra, deben realizarse con absoluto respeto al \\
equilibrio ecológico y la sanidad ambiental, sólo así, la vida y toda actividad hu- \\
mana serán posibles. En ese sentido, el principio 8 de la Declaración de Río de \\
1992, establece que "Para alcanzar el desarrollo sostenible y una mejor calidad de \\
vida para todas las personas, los Estados deberán reducir y eliminar las modalida- \\
des de producción y consumo insostenibles y fomentar políticas demográficas \\
apropiadas".
\end{tabular}

Fuente: Elaboración propia, 2021.

Teniendo en cuenta lo expuesto, se considera que en Costa Rica existe el desafío de propiciar un intenso debate orientado por una perspectiva de complejidad que permita: discutir la posibilidad, dentro de un marco pluralis, de introducir un sólido y reforzado capítulo de garantías ambientales en Costa Rica. Ese capítulo sería de gran relevancia por tres motivos: (1). Por un lado, daría mayor fundamento y legitimidad a las regulaciones infra-constitucionales en materia ambiental, evitando posibles mareas políticas de flexibilización y retrocesos ambientales. Así, habría control reforzado de decisiones mayoritarias contrarias a minorías en situaciones de injusticia ambiental y contrarias a la sustentabilidad ambiental; (2). Exigiría a la Sala Constitucional y a los tribunales en general, una hermenéutica jurídica ecológica más progresiva, consistente

\footnotetext{
${ }^{23}$ Voto disponible en: https://nexuspj.poder-judicial.go.cr/document/sen-1-0007-583694. Acceso en: 21 abr. 2021
} 
El ambiente ecológicamente equilibrado como derecho fundamental de la tercera dimensión. Reflexiones a partir de la tutela constitucional de Costa Rica

y apegada a los modernos principios del derecho ecológico; y, (3). Permitiría incorporar la protección efectiva de poblaciones tradicionalmente invisibilizadas, sujetas a mayores riesgos ecológicos y situaciones de injusticias ecológicas.

Además de lo indicado, la discusión referente a la introducción de ese capítulo constitucional ambiental podría permitir un profundo análisis sobre las posibilidades de un nuevo paradigma ecológico que supere el marcado antropocentrismo vigente en la actual norma constitucional.

La complejidad ecológica del Antropoceno exige lo que Winter llama de sustentabilidad fuerte en la cual

(...) la biosfera adquiere una importancia "fundamental". La economía y la sociedad son socios más débiles, ya que la biosfera puede existir sin los humanos, pero los humanos ciertamente no pueden existir sin la biosfera. Por lo tanto, el ser humano, a la vez que explota la naturaleza, debe respetar sus limitaciones, necesidad que puede satisfacer al poseer el potencial de la razón y, por lo tanto, las normas alternativas para ponderar el comportamiento $(2009$, p. 4$) .{ }^{24}$

Según Peralta (2019, p.155)

En síntesis, una pirámide de la sustentabilidad ambiental fuerte tiene, en su base, un parámetro precautorio, amparado en el conocimiento científico más adecuado que deberá considerar la capacidad de resiliencia de la Naturaleza de forma que sean respetados sus límites biofísicos. Se trata del pilar inicial, que deberá determinar si, en un segundo momento es posible realizar un análisis de ponderación en el cual sean considerados 5 elementos: Ecológicos (evaluación de posibles impactos), sociales, económicos, políticos, geográficos y tecnológicos. La imagen 1, refleja esa nueva concepción de sustentabilidad.

Los impactos ambientales, inevitablemente causados por las acciones antropogénicas, deberán ser realizados respetando los limites y la capacidad de la Naturaleza, de forma que no sean una amenaza para las futuras generaciones, ni para las otras especies. Lo que es tolerable es el impacto ambiental que respeta las fronteras de riesgo ecológico; por su parte, el daño ambiental, que es irreversible, atemporal, sinergético, carente de justicia ecológica, ese daño no es aceptable.

La discusión sobre ese nuevo pacto verde en la Constitución Política de Costa Rica podrá ser guiada por la Declaración de la UICN/2016. Conforme indicó Peralta (2019), esa Declaración en su apartado segundo (II) reconoce 13 principios -generales y emergentes- que deberán nortear el EED. En síntesis, de acuerdo con Peralta (2019, p. 156) esos principios determinan:

1. El reconocimiento intrínseco del valor de la Naturaleza, más allá de cualquier fin utilitarista. Ese reconocimiento exige el deber de todos -Estado, entidades, ciudadanos- de proteger la Naturaleza, respetando sus límites biofísicos, su capacidad de resiliencia y la evolución de los procesos ecológicos;

2. El derecho humano al ambiente ecológicamente equilibrado, con una dimensión intrageneracional e intergeneracional;

3. La consolidación de un derecho ambiental con una responsabilidad prospectiva capaz de adoptar normas de protección y restauración que permitan mantener y mejorar la resiliencia de los ecosistemas. Se resalta la función ecológica de la propiedad;

4. La aplicación del Principio In Dubio Pro Natura, en los diversos procesos de decisión, cuando exista duda sobre el riesgo o peligro ambiental;

${ }^{24}$ Traducción propia del texto original consultado en portugués. 


\begin{abstract}
5. El carácter integrador, pluralista, multicultural y holístico del $E E D$, debiendo promover la igualdad de género, la participación de grupos minoritarios y vulnerables, y el reconocimiento de los derechos de los pueblos indígenas y tribales;

6. La importancia de los principios de no regresión y de progresividad, para garantizar y mejorar las normas jurídicas ambientales y el acceso a la justicia, con el apoyo de los conocimientos científicos más recientes.
\end{abstract}

Explica Leff (2006, p. 133-134) que la sustentabilidad ecológica es un criterio normativo para reconstruir el orden económico; problematiza y cuestiona las formas de conocimiento, los valores sociales y las propias bases de producción. Un nuevo constitucionalismo ambiental debe partir de un pensamiento inclusivo e holístico que respete a las culturas con sus cosmovisiones y filosofías de vida, fundamentado por una ética de la alteridad y de la idea de responsabilidad con la naturaleza y con la dinámica de los procesos ecológicos. En esa nueva concepción la Naturaleza deberá ser vista como potencial de vida y no como un simple costo del desarrollo.

\title{
CONCLUSIONES
}

La protección del ambiente natural es también la protección de la libertad. La dimensión de los problemas ecológicos exige reconocer el derecho a un ambiente ecológicamente equilibrado como un derecho humano indispensable para vivir en condiciones de dignidad. Se trata de uno de los llamados derechos de tercera dimensión, conocidos como derechos de solidaridad o fraternidad. Los derechos de solidaridad han venido a conformar el contenido de la dignidad humana, ampliando su ámbito de protección. Los derechos de solidaridad pretenden materializar las demandas de la sociedad del riesgo de la segunda modernidad, y tienen un fuerte contenido humanista que exige responsabilidades de carácter global. Estos derechos se caracterizan por su titularidad difusa. El derecho fundamental al ambiente surge como consecuencia de la contaminación de las libertades; pretende limitar la libertad para protegerla.

La constitucionalización del ambiente es un fenómeno que refleja claramente la relevancia de la cuestión ambiental en nuestro tiempo y la exigencia de una transformación del modelo de desarrollo económico implantado a partir de la Revolución Industrial.

El derecho fundamental a un ambiente ecológicamente equilibrado tiene una doble funcionalidad: subjetiva y objetiva. Se trata de un derecho fundamental de los ciudadanos y un valor común de la sociedad que orienta y guía la conducta de los individuos y dirige la acción del Estado. Este derecho tiene un status negativus (aspecto defensivo) y un status positivus (aspecto prestacional). Es un derecho-deber basado en el valor de la solidaridad y guiado por los principios de precaución, sustentabilidad, esencialidad ambiental, progresividad, no regresión y justicia ecológica. Esta perspectiva de derecho-deber, por un lado, permite una proyección particular de carácter intergeneracional y, por otro, una protección interespecies guiada por una ética de la sustentabilidad.

El moderno Estado Ecológico de Derecho debe conciliar los derechos liberales, los derechos sociales y los derechos ecológicos derechos y los derechos ecológicos en un único proyecto político jurídico.

En el caso concreto de la Constitución de Costa Rica el derecho al ambiente está expresamente previsto en el artículo 50. No obstante, conforme analizado, se trata de una norma redactada y construida en diferentes momentos históricos, con poca coherencia técnica, anclada en una perspectiva de sostenibilidad débil y en un marcado antropocentrismo. 
El ambiente ecológicamente equilibrado como derecho fundamental de la tercera dimensión. Reflexiones a partir de la tutela constitucional de Costa Rica

En las próximas décadas, Costa Rica tiene el desafío de incentivar un debate, a partir de un paradigma de complejidad, que permita la introducción de un capitulo constitucional ambiental que fundamente y legitime las normas ecológicas infraconstitucionales, las acciones políticas y la ciudadanía ecológica. Ese capítulo ambiental permitirá el desarrollo y consolidación de una jurisprudencia constitucional orientada por una fuerte hermenéutica jurídica ecológica que no deberá estar pautada por la clásica idea antropocentrista de sostenibilidad débil que ha imperado desde 1993.

\section{REFERENCIAS}

ALEXY, Robert. Teoría de los derechos fundamentales. Traducción de Ernesto Garzón Valdés. Madrid: Centro de Estudios Políticos y Constitucionales, 2001.

BENJAMIN, Antônio Herman V. Constitucionalização do ambiente e ecologização da Constituição brasileira. In: CANOTILHO, José Joaquim Gomes; LEITE, José Rubens Morato (orgs.). Direito constitucional ambiental brasileiro. São Paulo: Saraiva, 2007.

CANO PECHARROMAN, Lidia. Rights of Nature: Rivers That Can Stand in Court. Resources 7, no. 1: 13. 2018. Disponible en: https://doi.org/10.3390/resources7010013. Acceso en: 22 abr. 2021

COLOMBIA. Corte Constitucional. Sentencia T-622/16. Disponible en: https://www.corteconstitucional.gov.co/relatoria/2016/t-622-16.htm. Acceso en: 21 abr. 2021

COLOMBIA. Corte Suprema de Justicia. Sala de Casación Civil. Sentencia STC 4360-2018 Disponible en: https://www.cortesuprema.gov.co/corte/wp-content/uploads/2018/04/STC43602018-2018-00319-011.pdf. Acceso: en 21 abr. 2021

COSTA RICA. ASAMBLEA LEGISLATIVA. Expediente n. 10.649

COSTA RICA. SALA CONSTITUCIONAL. Voto 3705-93. Disponible en: https://vlex.co.cr/ vid/-497243742. Acceso en: 21 abr. 2021

COSTA RICA. SALA CONSTITUCIONAL. No 01763-1994. Disponible en: https://nexuspj. poder-judicial.go.cr/document/sen-1-0007-95161. Acceso: en abr. 2021

COSTA RICA. SALA CONSTITUCIONAL. N . 6938-2000 Disponible en: https://nexuspj.poder-judicial.go.cr/document/sen-1-0007-138238. Acceso en: 21 abr. 2021

COSTA RICA. SALA CONSTITUCIONAL. No 01594-2013. Disponible en: https://nexuspj. poder-judicial.go.cr/document/sen-1-0007-566169. Acceso en: 21 abr. 2021

COSTA RICA. SALA CONSTITUCIONAL. No 10540-2013. Disponible en: https://nexuspj. poder-judicial.go.cr/document/sen-1-0007-583694. Acceso: en 21 abr. 2021

FENSTERSEIFER, Tiago. Direitos fundamentais e proteção do ambiente. A dimensão ecológica da dignidade humana no marco jurídico-constitucional do Estado socioambiental de direito. Porto Alegre: Livraria do Advogado, 2008.

GARCIA, Maria da Glória F.P.D. O lugar do direito na protecção do ambiente. Coimbra: Almedina, 2007.

GLOBAL FOOTPRINT NETWORK. Disponible en: https://www.footprintnetwork.org. Acceso: en 22 abr. 2021. 
JIMÉNEZ HERNÁNDEZ, Jorge. El tributo como instrumento de protección ambiental. Granada: Comares, 1998.

LEFF, Enrique (coord.). La complejidad ambiental. 2. ed. México: Siglo XXI, 2003.

IORNS MAGALLANES, Catherine J. Nature as an Ancestor: Two Examples of Legal Personality for Nature in New Zealand. Vertigo - la revue électronique en sciences de l'environnement [Online], Hors-série 22 | septembre 2015. Disponible en: http://journals.openedition.org/ vertigo/16199 Acceso en: 20 abr. 2021.

MATEO, Ramón Martín. Tratado de derecho ambiental, v. I, cit., p. 81; Tratado de derecho ambiental, v. I, Madrid: Trivium, 1991.

NABAIS, José Casalta. O dever fundamental de pagar impostos: contributo para a compreensão constitucional do estado fiscal contemporâneo. Coimbra: Almedina, 1998.

OST, François. A natureza à margem da lei: a ecologia à prova do direito. Lisboa: Piaget 1997.

PERALTA, Carlos. E. El nuevo paradigma de la sustentabilidad fuerte como pilar del Estado Ecológico de Derecho. Revista Jurídica Da FA7, Fortaleza, v. 16, n. 2, 2019. Disponible en: https://periodicos.uni7.edu.br/index.php/revistajuridica/article/view/1182 Acceso en: 22 abr. 2021.

PERALTA, Carlos E. A Justiça Ecológica como novo paradigma da Sociedade de Risco Contemporânea. Revista Direito Ambiental e sociedade. Caxias do Sul, v. 1, n. 1, p. 251-271, jan./jun. 2011.

TORRES, Ricardo Lobo A cidadania multidimensional na era dos direitos. In:

Teoria dos direitos fundamentais. 2. ed. Rio de Janeiro: Renovar, 2001. (org.).

VICENTE GIMÉNEZ, María Teresa (coord.). Justicia ecológica y protección del medio ambiente. Madrid: Trotta, 2002.

WINTER, Gerd. Um fundamento e dois pilares: o conceito de desenvolvimento sustentável 20 após o Relatório Brundtland.In: MACHADO, Paulo Affonso Leme; KISHI, Sandra Akemi Shimada (org.). Desenvolvimento sustentável, OGM e responsabilidade civil na União Europeia. Tradução de Carol Manzoli Palma. Campinas: Millennium, 2009.

Submetido em: 28 abr. 2021.

Aceito em: 25 maio 2021. 